\title{
Planning for tiny houses
}

\author{
Heather Shearer ${ }^{a}$, Valerie Bares ${ }^{b}$, Rikki Pieters ${ }^{b}$, Beth Winkle ${ }^{c}$ and Kate Meathrel ${ }^{d}$

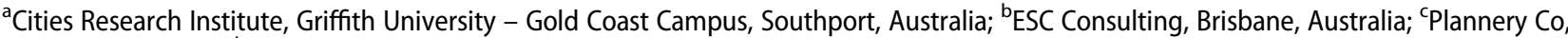 \\ Brisbane, Australia; ${ }^{d}$ Tiny Consulting, Brisbane, Australia
}

\begin{abstract}
The tiny house movement is an emerging trend towards building very small houses. It originated in the United States of America in the late 1990s, largely in response to housing affordability issues and a desire to live more sustainably. It is increasingly popular in Australia yet remains a niche market largely due to non-recognition within planning schemes and inconsistent local laws. Nonetheless, tiny houses could address some pressing urban housing problems, such as housing affordability and energy inefficiencies of poorly designed, large suburban houses. This paper reports on the development of the Tiny House Planning Resource for Australia, 2017, a collaborative report aimed at assisting planners, policy makers and the wider community to better understand the emerging tiny house movement and the model's potential to contribute to greater choice in housing supply and diversity. It uses a case study focussing on South East Queensland (SEQ) to explore councils' appetite and readiness regarding some tiny house options. It concludes tiny houses have significant potential to be a catalyst for infill development in the 'missing middle', either as tiny house villages, or by altering land use planning frameworks to allow both homeowners and tenants to situate well designed tiny houses on suburban lots.
\end{abstract}

ARTICLE HISTORY

Received 28 May 2019

Accepted 29 May 2019

\section{KEYWORDS}

Tiny houses; missing middle; granny flats; housing affordability

\section{Introduction}

Housing affordability is a perennial problem in Australia, and the country consistently ranks as one of the least affordable housing markets in the Organisation for Economic Co-operation and Development (OECD) (Cox and Pavletich 2015). This trend shows no signs of slowing, with Sydney, Melbourne, Adelaide and Brisbane ranked in the top 20 least affordable cities (Cox and Pavletich 2018).

Even more pressing is rental unaffordability. There are limited housing options for Australians on low incomes, income support payments or pensions (Anglicare Australia 2017). The proportion of the available housing stock that is both affordable and appropriate for people receiving benefits ranges from $0.007 \%$ (single, youth allowance) to $27.56 \%$ (couple on minimum wage, with children, FTB A) (Anglicare Australia 2017).

Unaffordable housing is also a social issue. Unequal spatial distribution of affordable housing impacts access to cultural and sporting activities and community cohesion (Berry 2003). Unaffordable housing also impacts the environment. The exodus of workers to distant suburbs increases private vehicle use, leading to air pollution, greenhouse gas emissions, and habitat destruction (Dodson and Sipe 2008).

Attempts to address this problem include increasing urban density, offering first time home buyers cash incentives, requiring new developments to set aside property for lower-income purchasers, and government-funded housing and rent assistance payments (Berry 2003). None of these, or the brief hiatus of the Global Financial Crisis of 2007/2008, have slowed escalating house prices, (Gurran, Gallent, and Chiu 2016) because the roots of housing unaffordability are a complex mix of both supply and demand-side factors. On the supply side are restrictive planning policies on the location and density of housing, large numbers of unsuitable developments, slow and inefficient development approval processes by Local Government Authorities (LGAs) and NIMBYism (Not In My Back Yard). On the demand side are the desire to live in closer proximity to public transport and employment; lowering of home loan interest rates and easy credit, favourable taxation policies for investment properties, such as negative gearing; in-migration and speculative demand.

A related issue is the distribution and size of dwellings. Australia also has some of the largest average house sizes in the OECD (Cox and Pavletich 2015), with the average dwelling being a detached house $(72.9 \%)$ with three or more bedrooms $(73.3 \%)$ of 207 square metres (241 square metres for new buildings) (ABS 2013, 2017; Cox and Pavletich 2015). Household numbers on the other hand, particularly the 'stereotypical' nuclear household, continue to decrease, concomitant with a rise in single, childless couples and group households. In 2016, nearly $60 \%$ of all 
households comprised one or two people, with $24.4 \%$ being one person households and $33.4 \%$ being two-person households (ABS 2017).

Australian cities are thus characterised by large areas of horizontal sprawl of detached houses, with a small central area of vertical sprawl of high-rise apartments. Figure 1 shows detached houses are mostly three bedrooms or larger, and units are mostly two bedrooms or smaller. Smaller households, the norm in Australia, have little choice than to live either in an apartment or a detached house that is often larger than they need or want.

A possible means to address unaffordable and unsustainable housing is tiny houses. The intentional tiny house movement is a growing phenomenon, particularly in Anglophone ex British colonies such as the US, New Zealand and Australia where housing affordability is a chronic issue. Tiny houses could help densify the 'missing middle' with low rise, medium density housing and ease affordability issues, particularly for older women, singles and younger people (Shearer, 2015). But the tiny house movement in Australia is in its infancy, with little extant scholarly research and few legislative guidelines. Tiny houses currently sit in a grey zone and are not recognised in most local or state planning legislation.

In response to this, a consortium of planners, consultants and academics devised the Tiny House Planning Resource for Australia 2017 (the Tiny House Resource), aimed ' ... to assist planners, policy makers and the wider community to better understand the emerging Tiny House movement within Australia and sets out to explore the model's potential to contribute to greater choice in housing supply and diversity' (Bares et al. 2017). In collaboration with Q Shelter, ESC Consulting, co-authors of the Tiny House Resource, also organised the Tiny House Deep Dive, a collaborative workshop aimed at identifying and solving some barriers preventing the establishment of tiny houses (Q Shelter and ESC Consulting 2018).

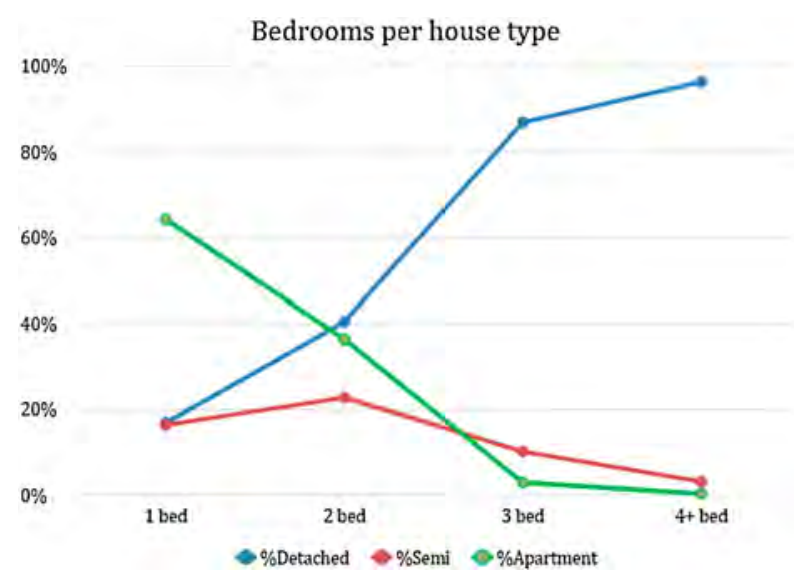

Figure 1. Bedrooms per house type Australia.

\section{Literature review}

\section{History of tiny houses}

From a global perspective, tiny houses are hardly unique; most people live in small dwellings. The tiny house movement however, was first popularised in the late 1990s in the US by architects and designers such as Sarah Susanka and Jay Schafer, who argued against the 'obesity' trend in residential architecture (Daloz 2016; Susanka and Obolensky 2001). They drew on past small/micro house typologies from as far back as the nineteenth Century, where tiny dwellings were romanticised in Thoreau's 'Walden' (Anson 2014).

Past typologies of smaller housing examples included the prefabricated post-war housing of the 1940s (created by the architect Jean Prouvé), the 1960s and 1970s alternative housing of the 'hippie' counterculture, including variants of tiny houses on wheels (Daloz 2016), and a variety of prefab and cottage-style houses (Jackson 2016).

Smaller houses became less popular with the rise of neo-liberalism and the consumer economic culture of the 1980s when the 'McMansion' archetype gained popularity. In the 1990s however, small but increasing numbers began questioning the trend to large, expensive houses and the minimum house size requirements of most US planning schemes. Most early tiny houses of the 1990s were on wheels, to avoid size requirements, to allow home ownership without the costs of land, and for 'freedom' (reflecting the strong antiestablishment values of some early adopters) (Anson 2014). Tiny houses can also be framed as a counter-cultural response to the stigma associated with 'trailer parks'.

The movement has continued to grow. Tiny houses have even been constructed as a response to natural disasters, for example, the Katrina Cottage, a 28.6 square metre unit developed after Hurricane Katrina. Likewise, in Australia, interest in the movement has increased significantly since 2013, when the movement first became popular on social media. Currently (2018), the largest tiny house Facebook page and group has over 50,000 followers.

\section{What is a tiny house?}

No formal definition of a tiny house exists in Australia, although in the US, 'Appendix Q* Tiny Houses' of the 2018 International Residential Code (IRC) defines a tiny house as ... 'a dwelling which is 400 or less square feet (37 square metres) in floor area excluding lofts', and sets out health and safety standards on lofts, ladders, ceiling height, stairways and emergency escape and rescue (ecobuilding.org 2017).

In Australia, research by Shearer \& Burton (2018) identifies three major types of tiny houses; Tiny Houses on Wheels (THoWs), potentially moveable tiny houses 
(i.e., on skids, containers or relocatable/prefab houses), and permanent tiny houses. Generally speaking, the accepted maximum size of a tiny house in Australia is around 37 square metres, with most THoWs under 20 square metres. Tiny houses are often detached, and have 'the character and functionality of a permanent house' as opposed to a caravan (Bares et al. 2017), with an environmental and economic sustainability and design ethos likely reflecting the architectural pioneers of the movement.

\section{Benefits of tiny houses}

Tiny houses offer a number of benefits, particularly affordability and sustainability. Most THoWs are cheaper than standard houses as they do not require the purchase of land, however, if you factor in costs/ square metre, tiny houses are often more expensive per square metre than larger houses; a 200 square metre project built house can cost upwards from $\$ 1000$ per square metre, while a tiny house of around 35 square metres can cost nearly 3 times as much per square metre. The main savings offered by tiny houses is not having to purchase land to build the house, especially as land in most Australian urban areas, is prohibitively expensive. Of course, it is still necessary to have access to land (either by paying rent or by doing work for the owner). Nonetheless, owning a THoW allows more flexibility in location, if it can park without contravening planning schemes or local laws, or if illegally parked, avoiding neighbour complaints.

The second-most important driver in the tiny house movement is environmental sustainability, and a related desire to minimise possessions. This pushback against consumerism and housing affordability problems apparently reflects a societal groundswell against the neoliberal consumerism of the late 1990s, which manifested in the suburban McMansions, planned obsolescence and proliferation of throwaway goods. Tiny houses are often off-grid and use significantly less power and water than standard houses and have a smaller ecological footprint. A 20 square metre house will use significantly less electricity and water in day to day operations than a 200 square metre house. Living in a tiny house can also reduce personal vehicle use (provided good access to quality public transport).

Finally, tiny houses have social benefits, allowing access to housing for those in lower socio-economic quintiles, such as young singles and couples and older single women. Interest in tiny houses is strong in women over 55, who are also the fastest growing demographic for homelessness in Australia (Shearer 2015; Petersen and Parsell 2015). Tiny houses can also increase the density of the urban area without major disruption to the existing urban landscape, in contrast to building high rise apartments (NewtonBrown 2017) Figure 2.

\section{Who wants tiny houses?}

Interest in tiny houses has grown markedly since 2013, with significantly more people now building or wanting to build a tiny house (Shearer 2015, 2017). Several companies now build tiny houses (mostly THoWs), and granny flat builders have proliferated, especially in response to the rising popularity of granny flats and the relaxation of legislation on letting these in some states (i.e., NSW and WA).

A survey found the majority of tiny house advocates are women (around 67\% of respondents), with nearly $80 \%$ over 40 (Shearer 2017). Tiny houses are also popular with singles, couples and those with small or

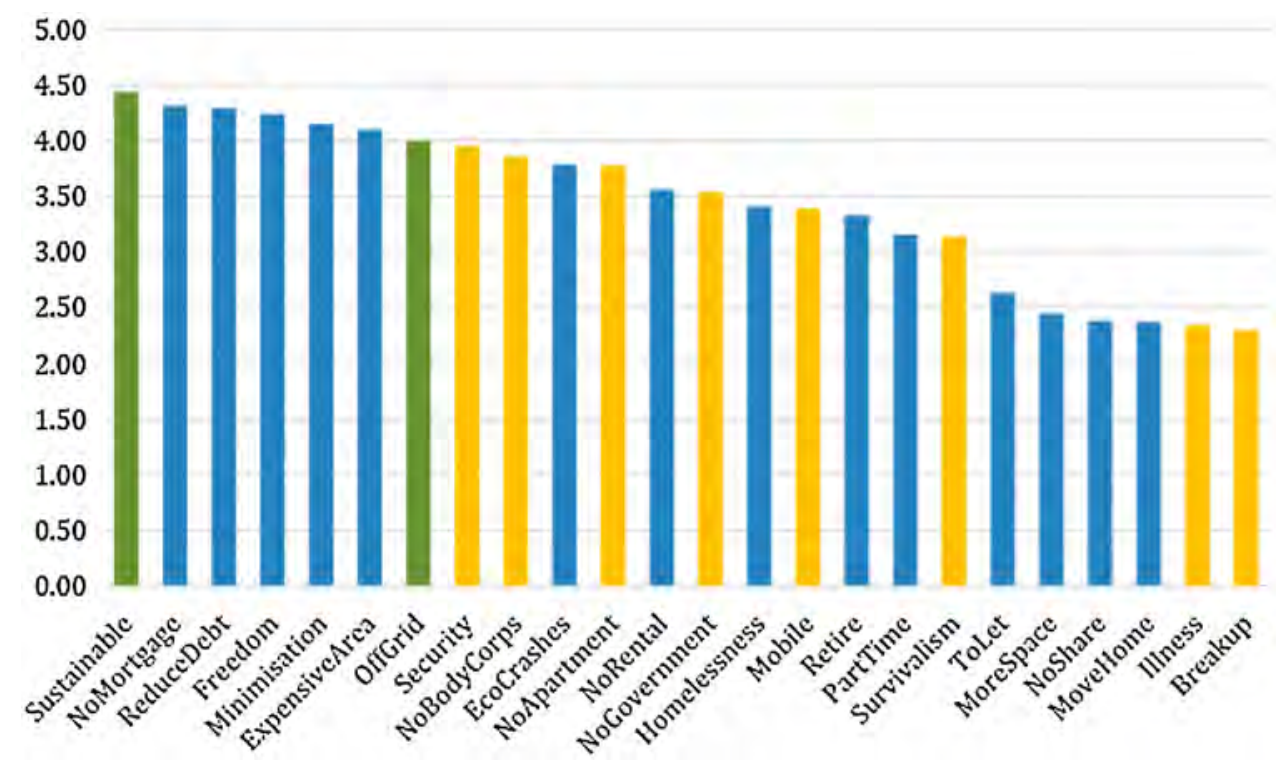

Figure 2. Tiny house drivers. 
younger families. For many, such as 'Millennials' seeking to move out of home/shared premises and older women, tiny houses offer the chance to own one's own home. This unwillingness to live in share houses or apartments differentiates tiny house advocates from those wanting merely to downsize their living arrangements. Many tiny house advocates want their own space, to have a garden and space for pets. A strong undercurrent of anti-establishment ideals is evident in the tiny house movement; making apartments, with their often restrictive body corporate rules (and the cost of body corporate fees) unpopular (Anson 2014). This may also mirror the 'Great Australian Dream' of living in a detached house with its own backyard; a place for privacy, greenspace for environmental benefits, cooling and reduction of water runoff, and a refuge from the stresses and trials of the world (Hall 2010; Gurran, Gallent, and Chiu 2016; Moran and Moran 2006).

\section{Barriers to tiny houses}

The growth and establishment of the tiny house movement is not without its barriers, some of which are significant (Shearer 2017). The most problematic are that LGA planning scheme provisions do not support tiny houses as a feasible housing option, and it is difficult for them to comply with the Building Code of Australia/National Construction Code (BCA/NCC) (or for THoWs, relevant State and Federal transport laws) (Shearer 2017). Notably, planning schemes in themselves do not create barriers to tiny houses, it is just that this form of housing has never been seriously contemplated for a range of reasons. Barriers also include the cost of purchasing or renting land in urban areas, and in areas zoned for multiple dwellings, it is not the highest and best use to build lower density structures such as tiny house villages. Finally, most LGAs restrict letting part of a property to a THoWs and there is no precedent in property law for this (discussed further in the following section) Figure 3.

\section{Planning for tiny houses}

Given the demand for and potential benefits of tiny houses, how can these be better incorporated into Australian cities? The Tiny House Resource and the Deep Dive investigated a number of tiny house options and explored how alterations to the planning and development framework and building/construction controls could accommodate and support this type of housing.

The following scenarios were analysed in the Tiny House Resource; granny flats, tiny backyard leases, tiny lots, tiny villages and tiny house parks. The Deep Dive workshopped tiny houses in intentional communities for women over 55, as homeless shelters on underutilised government land, and granny flats revisited (for permanent or tourism rentals). This case study considers how the three development scenarios described above could be incorporated into current legislation; permanent granny flats, tiny backyard leases for permanent residence, and short stay tiny house residences (for holiday letting) (Q Shelter and ESC Consulting 2018; Bares et al. 2017).

\section{The granny flat (accessory dwelling unit)}

Granny flats, ${ }^{1}$ if subordinate to the primary dwelling house, are an accepted form of housing type in Queensland planning schemes. Most SEQ LGA's (except for Logan City and Ipswich City), require that a granny flat to be inhabited by members of the primary

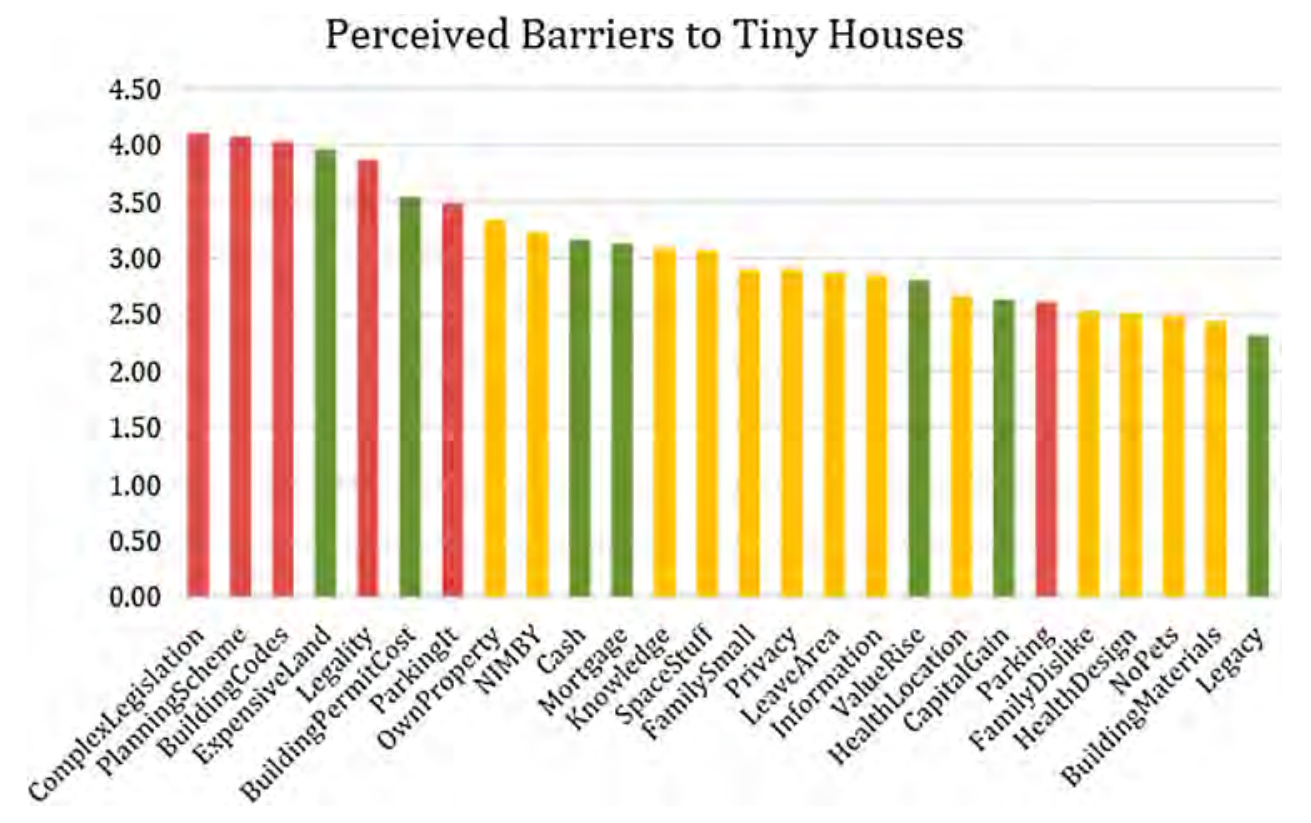

Figure 3. Perceived barriers to Tiny Houses. 
'household'. 'Household' is generally defined in accordance with Schedule 24 of the Queensland Planning Regulation (2017) as, '1 or more individuals who(a) live in a dwelling with the intent of living together on a long-term basis; and (b) make common provision for food and other essentials for living.' In NSW, granny flats can be leased to anyone, leading to a boom in granny flat construction (Figure 4).

Each Queensland LGA has different planning regulations regarding granny flats but they all require approval as a Class 1 building, requiring site surveys, contour plans, submission of building plans, etc. LGAs differ in other requirements such as gross floor area, distance from the main property, setbacks, coverage, minimum total lot size and connections to utilities, etc. Some LGAs have more stringent requirements than others, and the larger urban LGAs appear more flexible. Of interest, Noosa Shire Council allows construction of a larger granny flat (65 vs. 45 square metres) if it has wheelchair access.

Granny flats offer many potential benefits. If they could be let to anyone, it could encourage urban densification and more affordable housing, provide ageing in place opportunities, and potentially assist families to accommodate on-site domestic support (i.e., child care, pet sitting, household maintenance and caretaking.). Granny flats also provide extra space for the changing needs of families (i.e., teenage and adult children). Building a granny flat on to existing property can be financially beneficial, as such properties appeal to the resale and rental markets, although they are relatively expensive to build. Being permanent additions to the land, it is relatively simple to get mortgage finance. While land ownership is usually a prerequisite, it is also possible to secure a First Home Owner grant for a granny flat built on a relative's land (Queensland State Government 2018).

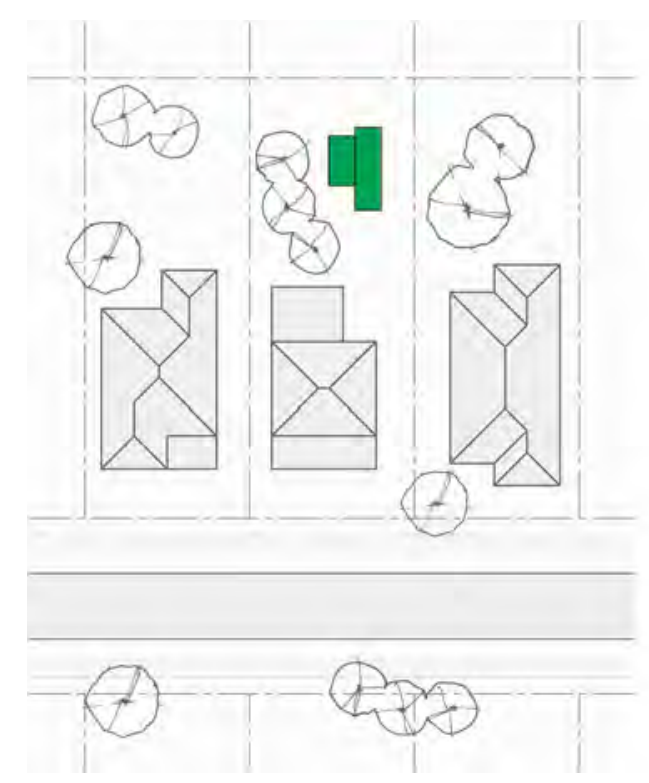

Figure 4. The granny flat.

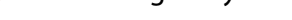

\section{Tiny backyard leases}

Tiny backyard leases assume a THoW is parked in a backyard on someone else's property and rent (or bartered arrangements) is paid to the property owner (or tenant). The legalities for this model are more tenuous than granny flats, and are largely dependent on how LGAs differentiate between 'temporary dwellings/ homes' and 'camping'. All SEQ LGAs permit a temporary home, usually requiring limited periods of occupation, generally (from a couple of weeks to a few months) while building a standard house. Specific regulations vary widely, with Logan City, Sunshine Coast and Noosa among the most proactive; for example, the Sunshine Coast Regional Council allows people to live in a range of different temporary accommodation including buses, tents and removable dwellings, with different time periods for each type (Sunshine Coast Regional Council 2018). Other LGAs require permits and some rural LGAs, such as Somerset, Lockyer Valley and Ipswich, are relatively inflexible. Residing in a temporary Caretaker's Dwelling is permitted, but this assumes the Caretaker is employed by the property owner (Figure 5).

THoWs are not recognised in any LGA and are mostly considered as caravans, which can trigger local laws on 'camping'. Camping is managed under Local Laws/Subordinate Local Laws rather than Planning Schemes; and anyone living temporarily on a property can be fined and/or evicted, particularly in response to neighbour complaints. Policies on 'camping' differ widely between LGAs, with some, such as Brisbane City being relatively flexible by allowing a person to reside in a caravan on private property provided no public nuisance is caused and the occupant/s have appropriate access to toilet and refuse disposal facilities (BDDRC 2016). Other councils prohibit any camping

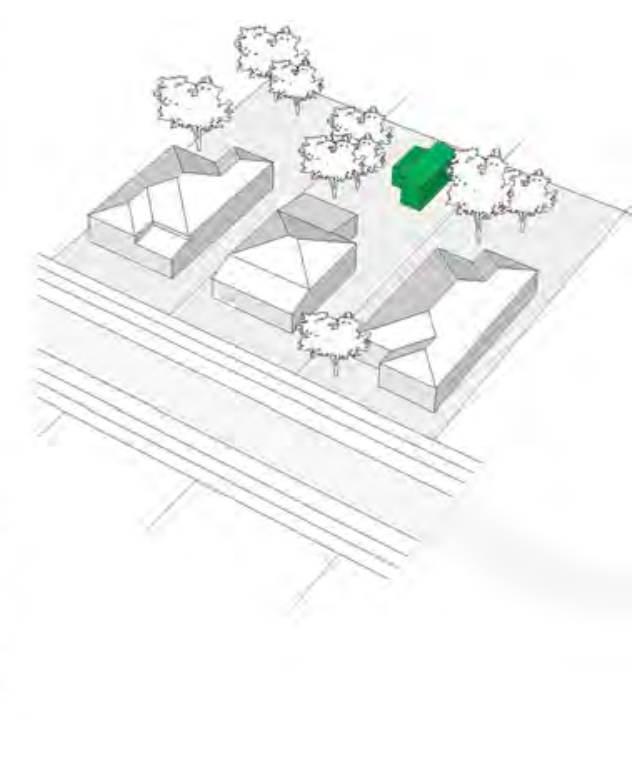



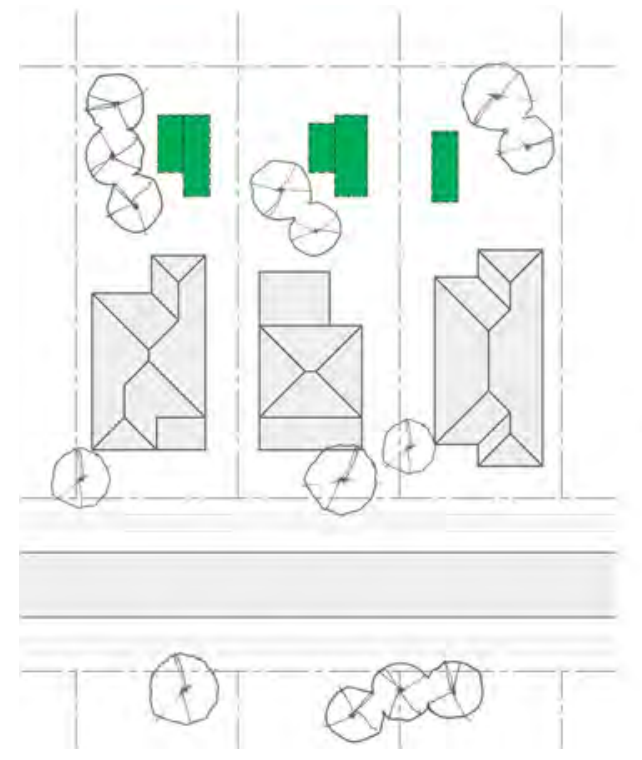

Figure 5. Tiny backyard leases.

on private property, for example, under Subordinate Local Law 16.6 (Camping Areas), the Gold Coast ' ... prohibits anyone from using a caravan on private land... Includes temporary or semi-permanent accommodation for residential or recreational purposes, including occupying or sleeping in, or attempting to occupy or sleep in, a tent, caravan or vehicle.' (Gold Coast City Council 2018).

Nonetheless, tiny backyard leases have significant advantages and are ideal for THoWs. This flexible option can provide landowners with additional income, enable rapid access to housing in booming regional areas, or in areas with environmental constraints such as flooding or bushfire. THoWs will not overload the existing infrastructure, although they may require additional parking.

\section{THoWs for tourism}

Some tiny house builders promote THoWs as suitable for short term tourist accommodation, such as Airbnb. Under this scenario, it is assumed the tiny house is owned by the landowner. While it is potentially feasible for a non-landowner to place a THoW on someone else's property, it would require a legal agreement, as there may be insurance, tax, public liability and possibly legacy implications.

Nearly all LGAs have codes for bed and breakfast/ short term accommodation or home-based businesses, with Logan City having a specific code for Airbnb (of note, Logan City has been one of the most proactive LGAs in SEQ for tiny houses) (Logan City Council 2018). Currently no specific legal precedents pertain to using a THoW or any other type of temporary tiny house as Airbnb, though some LGAs require approval as a bed and breakfast; 'You would not be able to holiday-let a tiny house as it would require

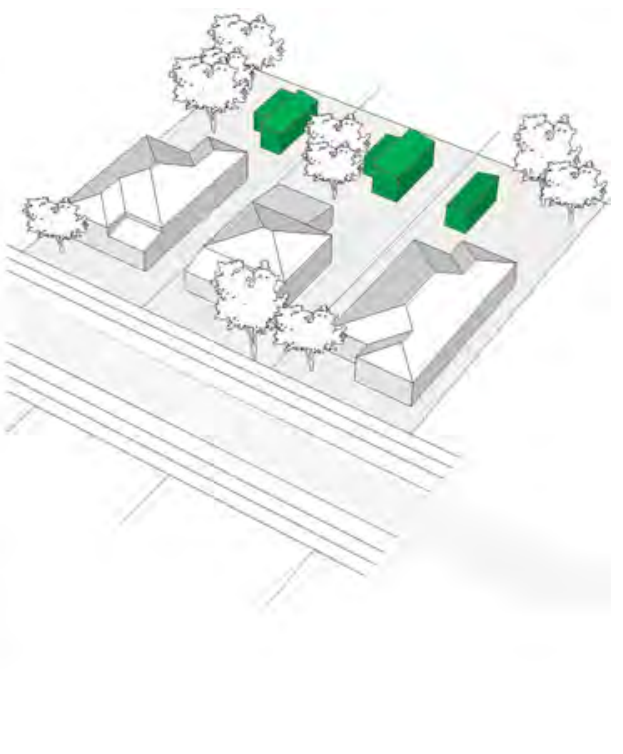

approval as a bed and breakfast if there was an existing house on site' (Noosa Shire Council 2018).

\section{Tiny lots}

Tiny lots are another means to include tiny houses in urban areas. These would start from about 150 square metres and could be titled as freehold or Community Title. The potential tiny house dweller could purchase the lot and build a tiny house, or rent a lot/existing tiny house. Queensland currently has a minimum lot size of 300 square metres, although some LGAs are considering allowing smaller lots, particularly near major transport corridors. In areas where the value of land is higher however, houses built on subdivided lots are often large (Hall, 2010; Figure 6).

\section{Tiny villages and tiny house parks}

Tiny villages could comprise a number of tiny houses on one lot (approximately 4-8) and would be similar to medium density developments. The resident would purchase the house under a Community Titles Scheme, and pay Body Corporate fees, and it could be let out. The owner would have rights to the land, as in current community titles schemes. Planning schemes do not currently support small units of accommodation, and market forces dictate that this type of proposal is mostly not the highest and best use (Figure 7).

Tiny house parks are similar to caravan parks and are more suitable for THoWs. Under this model, the owner has no rights to the land. Existing caravan parks could easily incorporate sections dedicated to tiny houses, with little, if any, change to legislation. Of note, caravan parks in desirable areas (i.e., with attractive amenity, or close to the beachside or the CBD) are under significant development pressure, 


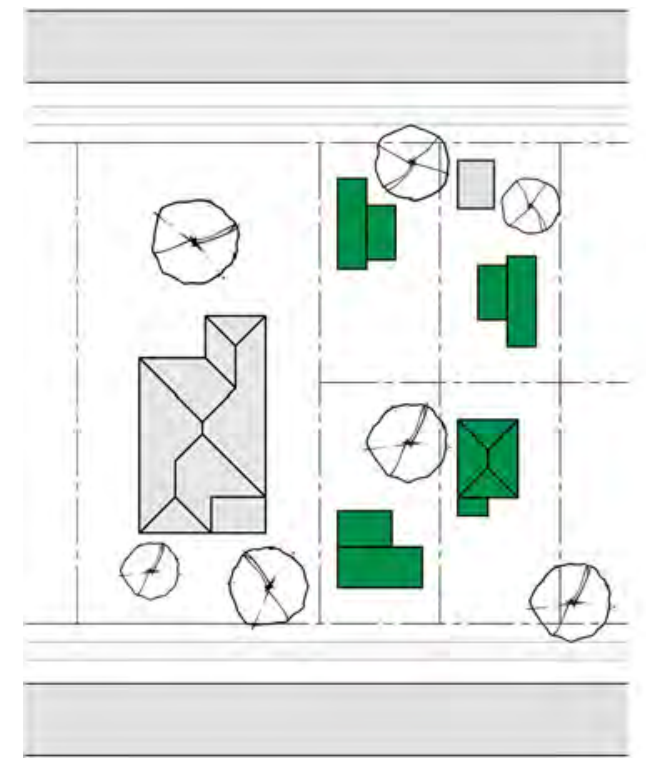

Figure 6. Tiny lots.

and tiny houses may not be the highest and best use of the land. Caravan parks in less desirable areas often have limited access to services and high frequency public transportation and may be stigmatised as places for 'permanents', who for various reasons, cannot access the rental market. This type of property is legal in Queensland.

\section{How can tiny houses become a supported form of housing?}

With the exception of a fixed granny flat, tiny houses are not recognised by the majority of planning schemes in Australia. Moreover, some sections of the Building Code of Australia (Volumes 1 and 2 of the National Construction Code (BCA/NCC)) (Australian Building Codes Board 2018) or the Queensland Development Code (QDC) (Queensland State Government 2015) would require some relaxation to ensure tiny houses

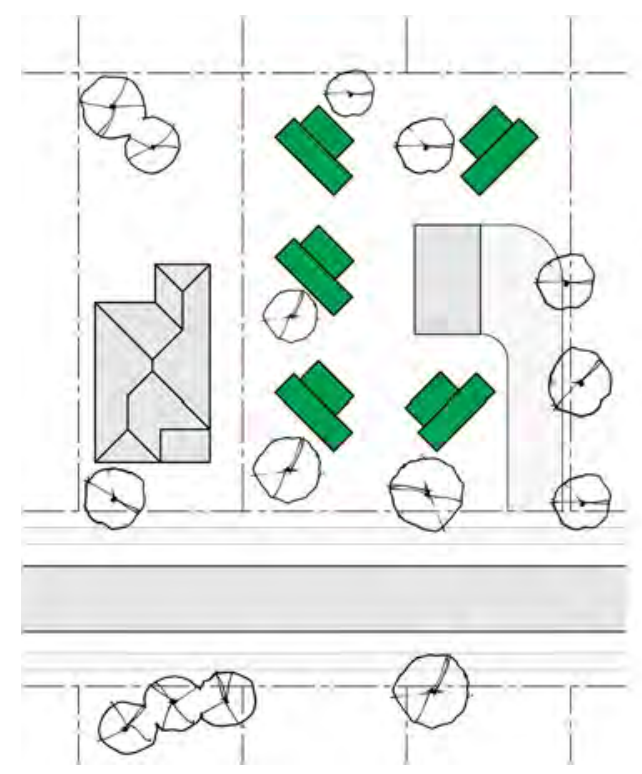

Figure 7. Tiny villages.

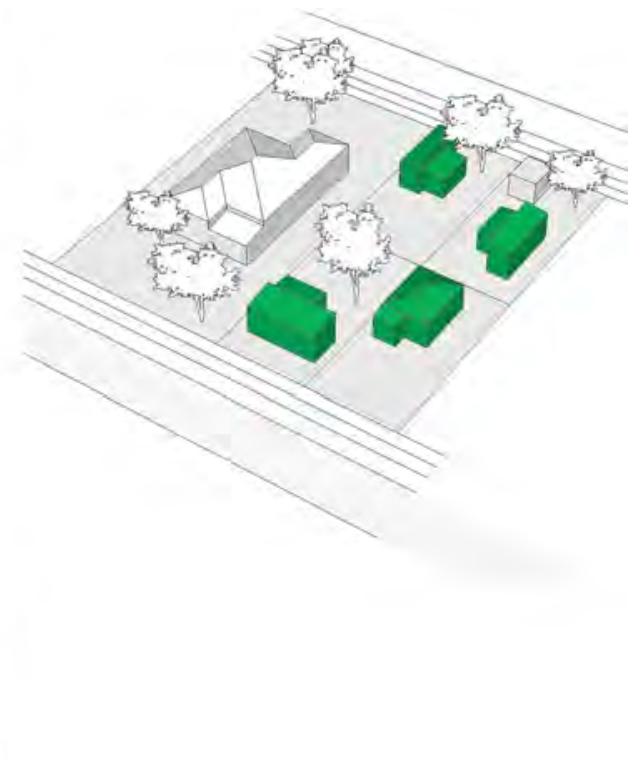

to be appropriately regulated under these instruments. It is difficult for THoWs to comply with the BCA/NCC and QDC, particularly for ceiling height, stairways and environmental performance (Q Shelter and ESC Consulting 2018) as they are simply not contemplated as part of the code.

If a tiny house cannot be categorised in a particular planning scheme, for example, as a granny flat or temporary dwelling, they typically fall under the relevant local law applying to camping on private lands. THoWs, however, are neither temporary dwellings (as people often choose to live in them permanently) nor are they caravans.

Regardless of their legal status, tiny houses are an increasingly popular housing form, particularly for certain demographics. They can provide a flexible housing option to support housing diversity and density. Tiny houses can be a sensitive and appropriate infill option that contributes to the existing housing stock in low to

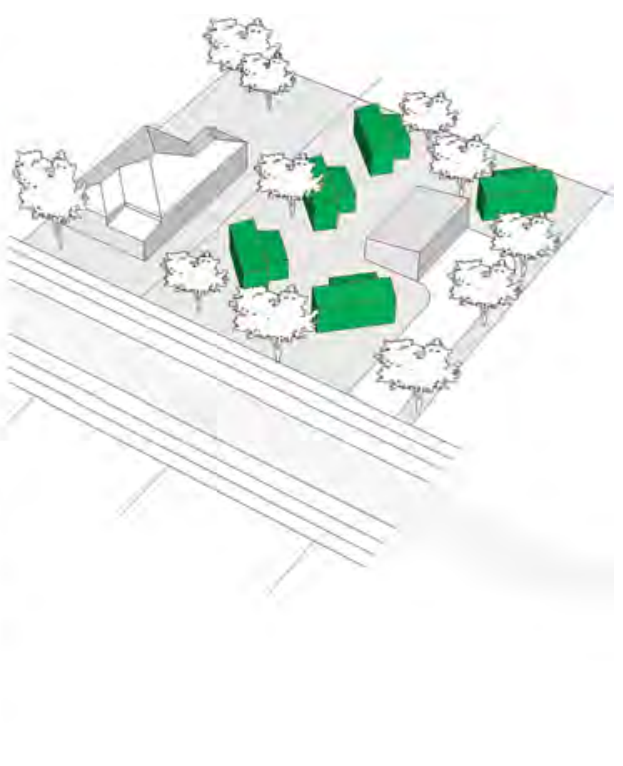

7. Tiny villages. 
medium density residential zones with relatively large lots (the 'missing middle').

This paper argues it is desirable for tiny houses, as an emerging form of housing within planning and development, to be recognised in legislation, including the BCA/NCC and QDC to ensure compliance with safety, design, residential amenity and infrastructure provision. Further, construction and building standards will need to be altered as some aspects of the BCA/NCC do not contemplate tiny houses (as per the IRC Code),and the QDC will need to be relaxed in a proposed tiny house appendix (as per the IRC Code (ICC 2017)), for example stairway construction and ceiling height (Bares et al. 2017).

Considering the current planning and development framework, tiny houses represent a semi-legal outlier, often hidden in rural areas, which results in current occupants being at risk of being moved because of potential complaints or council restrictions. This may appeal to an anti-establishmentarian subsector of the movement, but may impede the inclusion of tiny houses into the mainstream urban fabric. The lack of controls on building standards could also result in sub-standard safety and increased risk for tiny house builders or inhabitants. So, how can tiny houses be incorporated into legislation as a regulated form of housing in urban areas? This paper now considers the planning and building legislative framework and suggests three options; incorporation in state policy and planning schemes, local laws and the QDC.

\section{State Planning Policy 2017}

The State Planning Policy 2017 (SPP) is a key component of Queensland's planning system, and outlines the state's interest in land use planning and development (DILGP 2017). The SPP is used in plan making and development assessment decisions. A state interest is defined under the Planning Act 2016 (the Act) and under the Act each local government planning scheme needs to set out integrated state, regional and local planning and development assessment policies for the LGA. The SPP sets out the requirement for providing a diverse, affordable and comprehensive range of housing options in accessible and well-serviced locations. Tiny houses can contribute to the state interest for planning for liveable communities and housing.

\section{South East Queensland Regional Plan}

The South East Queensland Regional Plan 2017 (also known as ShapingSEQ) is the regional plan for the South East Queensland region (Queensland State Government 2017b). ShapingSEQ provides a regional framework for growth management and infrastructure and sets planning direction for sustainable growth, global economic competitiveness and high-quality living.
In achieving the population growth anticipated by ShapingSEQ, tiny houses can contribute to housing affordability and increasing residential densities within established residential communities without undermining the character and pattern of development. Tiny houses could be included within the "Hidden density/small scale infill' housing achieving densities of between 15 and 20 dwellings/hectare.

\section{Planning schemes}

Under the Planning Act 2016 (Qld), planning schemes are means by which a LGA provides for strategic planning and development, taking community aspirations, local factors and State Government interests into account (Queensland State Government 2016b; DILGP 2018). The Planning Regulation 2017 (Qld), is subordinate legislation which sets out, amongst other things, standards for planning schemes, assessment categories, definitions, referrals etc. Full and proper planning requirements/ parameters for tiny houses could be incorporated into the Planning Regulation 2017 (Qld) but such an amendment would need to be supported and undertaken by the State government, along with consultation with local government and the community.

LGAs change planning schemes when required to do so by the State or legislative timelines (every ten years) or as they determine necessary. The State Government provides a Statutory Guideline, Making and Amending Local Planning Instruments, with steps for major, minor and planning scheme policy amendments (Department of Infrastructure, Local Government and Planning (DILGP), 2017). Incorporating a new assessment type such as a new dwelling category would likely be considered a major amendment. This process is relatively complex and time consuming and includes public consultation. Along with support from the State Government and LGA's recognition of tiny houses in the Planning Regulation 2017 (Qld) and planning scheme's is the optimal way for tiny houses to be recognised in planning law. Whilst it is acknowledged that changing legislation can be a lengthy process; the inclusion of tiny houses within the planning framework provides certainty to the community, lending institutions and investors and a regulatory foundation to be able to deliver tiny houses in appropriate circumstances.

\section{Local laws}

Individual LGAs control the local laws process, but the Local Government Act 2009 (Qld) imposes specific requirements, including checking for State Interests and public notification (Queensland State Government 2009). The State Government Guidelines on Drafting Local Laws (Queensland State Government 2016a) 
also requires local laws to be consistent with the Local Government Act 2009 (Qld), with the exception of Brisbane (City of Brisbane Act 2010 (Qld))(Brisbane City Council 2010).

Local laws control activities such as camping areas, rental accommodation, etc. In the case of THoWs, a local law on rental accommodation could be amended (or a subordinate local law specifically on tiny houses enacted) to control the siting, licensing, control of wastes, etc. for the tiny house. This could be a quick and effective way for LGAs to recognise THoWs but is only a short-term solution, as tiny houses still require recognition in planning schemes and/or in State planning provisions and the QDC.

\section{Queensland development code}

The QDC is part of the Building Act 1975 (Qld) (Queensland State Government 1975), and consolidates Queensland specific building standards into a single document. It incorporates both mandatory and advisory standards (Queensland State Government, 2015). The advisory standards are considered model standards for LGAs to incorporate, with appropriate local changes, into planning schemes (Queensland State Government, 2015). If any inconsistency, the QDC takes precedence over the BCA.

The QDC has a number of sections in which tiny houses could be considered; including Part 1.0 Siting and amenity - Detached housing and duplexes; Part 3.0 Special buildings and Part 4.0 Building sustainability, or in the non-mandatory parts. It may be appropriate to include tiny houses in Part 3.0 Special buildings. Incorporating tiny houses into the QDC would be a powerful lever to persuade LGAs to recognise this housing form.

\section{Discussion and conclusion}

Tiny houses are a viable option for permanent or temporary housing to improve affordability in Australian urban areas. They can be environmentally sustainable, contribute to housing and residential density in the 'missing middle' and offer attractively designed and innovative homes. Tiny houses can effectively increase urban density by infill development in already developed, older suburbs with established connections to employment hubs, public transport and other urban amenities.

Strong interest in and demand for tiny houses is evident from a wide range of demographics; such as younger people wishing to enter the housing market, older singles, long term renters and those on reduced incomes. Tiny houses can facilitate a wider diversity of people living closer to the city, with positive social and economic benefits. Existing landowners can lease part of their property to tiny house owners, or move into a tiny house and let the larger house as they become older or life circumstances change. The tiny house typology has potential for 'ageing in place'.

Nonetheless, the legal status of tiny houses remains unclear and this prevents many from taking advantage of this housing form. Some types of tiny houses, such as granny flats, are accepted forms of development, with some limitations such as being subordinate to the primary dwelling, and also require ownership of land.

THoWs are undefined in planning legislation. Although they are treated as 'caravans' under transport regulations, they are dissimilar, and are not intended to be regularly moved. Nonetheless, they remain unregulated as permanent dwellings in all LGAs, with the exception of Brisbane City and Logan City. They are legal as temporary dwellings in most LGAs, but only if the landowner is building a permanent dwelling or if used as caretaker's accommodation.

Granny flats used as Airbnb are generally accepted, although THoWs are in a relatively 'grey' area. Few LGAs have policies on Airbnb, but these generally fall under policies on bed and breakfast accommodation. If permitted, it can be quite expensive and onerous to get LGA permits for tourist accommodation.

The current status of tiny house legislation is unclear, with an identified need for consistency across planning schemes (Q Shelter and ESC Consulting 2018). This paper recommends leadership from state planning authorities where state-wide planning provisions could be prepared in consultation with local authorities and local communities. Local authorities could adapt and include specific provisions and requirements which would be necessary to best suit individual communities. This would provide the tiny house sector with certainty and confidence in terms of development proposals and financing options.

Practically, incorporating tiny houses into legislation is possible, and could be achieved with recognition in state and regional planning processes and in LGA planning schemes, Local Laws and QDC provisions. It is also suggested that LGAs be approached to exempt THoWs from local law camping prohibitions until they can be included legitimately in planning schemes or specific local laws clearly differentiating between THoWs and other temporary mobile dwellings, such as caravans.

Pertaining to the revision of a planning scheme, a model code could be devised specifically for tiny houses, with provisions made, as per temporary dwellings, for design and architecture, residential amenity, waste and water provision and removal, siting and layout requirements, etc. In this way, LGAs can amend this according to the specific local area (i.e., planning scheme zones, etc.). This would also allow local authorities to regulate and manage the planning and approvals processes, building process, health and safety aspects, infrastructure provisions and titling, where appropriate. 


\section{Note}

1. A granny flat (or accessory dwelling unit) is a small secondary dwelling, either connected or at a short distance from the main house, commonly used to house adult children or elderly parents (i.e. granny)

\section{Acknowledgements}

The authors would also like to acknowledge the work of the following people: Lara Nobel, Andrew Carter and Fiona Caniglia.

\section{Disclosure statement}

No potential conflict of interest was reported by the authors.

\section{References}

ABS. 2013. "4364.0.55.004 - Australian Health Survey: Physical Activity.” http://www.abs.gov.au/ausstats/abs@. nsf/Lookup/4364.0.55.004Chapter4002011-12.

ABS. 2017. “Census Quick Stats, 2016 Census.” http://www. censusdata.abs.gov.au/census_services/getproduct/ census/2016/quickstat/036?opendocument.

Anglicare Australia. 2017. "Rental Affordability Snapshot." Anglicare, Canberra, Australia.

Anson, April. 2014. "The World is my Backyard": Romanticization, Thoreauvian Rhetoric, and Constructive Confrontation in the Tiny House Movement." From Sustainable to Resilient Cities: Global Concerns and Urban Efforts 14: 289-313. https://doi.org/ 10.1108/s1047-004220140000014013. ://WOS:000358064900014

Australian Building Codes Board. 2018. "National Construction Code." In edited by Australian Building Codes Board.

Bares, V., R. Pieters, L. Nobel, B. Winkle, K. Meathrel, H. Shearer, and F. Caniglia. 2017. "A Place for Tiny Houses. Exploring the possibilities: Tiny House Planning Resource for Australia, 2017.” (Brisbane). http://www.tinyhousecompany.com.au/s/20170531-tinyhouse-planning-resource_v1-0sml.pdf.

BDDRC. 2016. Decision Appeal no 39-16. Housing and Public Works, Building and Development Dispute Resolution Committees. http://www.hpw.qld.gov.au/ SiteCollectionDocuments/FinalDecision39-16.pdf.

Berry, Mike. 2003. "Why is it Important to Boost the Supply of Affordable Housing in Australia-and how can we do it?" Urban Policy and Research 21: 413-435.

Brisbane City Council. 2010. City of Brisbane Act, 2010.

Cox, W., and H. Pavletich. 2015. "International Housing Affordability Survey.” Demographia. (www.demographia. com).

Cox, W., and H. Pavletich. 2018. International Housing Affordability Survey. 14th Annual Demographia International Housing Affordability Survey. London School of Economics (London). http://demographia.com/dhi.pdf.

Daloz, K. 2016. "When Tiny Homes Hit the road. Why Tiny Homes on Wheels were Perfect for the 1960s counterculture." Curbed. https://www.curbed.com/2016/9/21/12955 504/mobile-tiny-homes-1960s-volkswagon-van.

DILGP. 2017. “State Planning Policy 2017.” https://dilgpprd. blob.core.windows.net/general/spp-july-2017.pdf.

DILGP. 2018. "Our Planning System." In edited by Racing and Multicultural Affairs Dept. of Local Government. Brisbane.
Dodson, J., and N. Sipe. 2008. "Shocking the Suburbs: Urban Location, Homeownership and Oil Vulnerability in the Australian City." Housing Studies 23 (3): 377-401. doi:10.1080/02673030802015619.

ecobuilding.org. 2017. “2018. Tiny Houses Appendix Q in International Residential Code.” http://www.ecobuilding. org/code-innovations/policy-profiles/2018-tiny-house-ap pendix-to-residential-code/tiny-house-appendix-q-as-pro posed.

Gold Coast City Council. 2018. "Subordinate Local Law 16.6 (Camping Areas)."

Gurran, Nicole, Nick Gallent, and Rebecca L. H. Chiu. 2016. Politics, Planning and Housing Supply in Australia, England and Hong Kong. New York: Routledge.

Hall, Tony. 2010. "Goodbye to the Backyard?-The Minimisation of Private Open Space in the Australian Outer-Suburban Estate." Urban Policy and Research 28 (4): 411-433. doi:10.1080/08111146.2010.496715.

ICC. 2017. "Overview of the International Residential Code ${ }^{\oplus}$ $\left(\right.$ IRC $^{\circledast) . ” ~ I n ~ I n t e r n a t i o n a l ~ C o d e ~ C o u n c i l . ~}$

Jackson, M. 2016. "The 'Tiny Houses' of the 20th Century." http://www.architectmagazine.com/design/culture/thetiny-houses-of-the-20th-century_o.

Logan City Council. 2018. "Fact Sheet. Airbnb Accommodation."

Moran, Alan J., and Alan J. Moran. 2006. The Tragedy of Planning: Losing the Great Australian Dream. Institute of Public Affairs Melbourne.

Newton-Brown, C. 2017. "Tiny Houses Should be Permitted in Australian Suburbs.” In The Australian. Sydney: News Corporation.

Noosa Shire Council. 2018. Bed and Breakfast accommodation in Noosa.

Petersen, M., and C. Parsell. 2015. "Homeless for the First Time in Later Life: An Australian Study." Housing Studies 30 (3): 368-391. doi:10.1080/02673037.2014.963522.

Q Shelter, and ESC Consulting. 2018. "Tiny House Deep Dive Workshop Report.” Brisbane, Queensland.

Queensland State Government. 1975. "Building Act, 1975.”

Queensland State Government. 2009. "Local Government Act."

Queensland State Government. 2015. "Queensland Development Code.” In edited by Dept. of Housing and Public Works. Brisbane.

Queensland State Government. 2016a. "Guidelines for Drafting Local Laws.” In Queensland.

Queensland State Government. 2016b. "Planning Act 2016."

Queensland State Government. 2017b. "South East Queensland Regional Plan: Shaping SEQ."

Queensland State Government. 2018. "Applying for a First Home Owner Grant.” https://www.qld.gov.au/housing/ buying-owning-home/first-home-check-eligibility.

Shearer, H. 2015. "The 'Tiny House' Movement: Its Implications for Housing Affordability and Urban Sustainability." In Australian Housing Researchers Conference, edited by University of Tasmania Housing and Community Research Unit. Hobart, Tasmania.

Shearer, H. 2017. "Interest in Tiny Houses is Growing, So Who wants them and Why?" In The Conversation.

Shearer, Heather, and Burton Paul. 2018. "Towards a Typology of Tiny Houses." Housing, Theory and Society 1-21.

Sunshine Coast Regional Council. 2018. "Sunshine Coast Regional Council Subordinate Local Law No. 1 (Administration) 2016 - Schedule 7 Establishment or occupation of a temporary home (Schedule 7)."

Susanka, Sarah, and Kira Obolensky. 2001. The not so big House: A Blueprint for the way we Really Live. Newtown, Connecticut: Taunton Press. 